\title{
Pure Micropapillary Rectal Carcinoma with CK7 and CK20 Coexpression and Loss of CDX2 Reactivity
}

\author{
Carcinoma Micropapilar Rectal Puro con Coexpresión \\ de CK7 y CK20 y Pérdida de Reactividad CDX2
}

Leonardo Saúl Lino-Silva

LINO-SILVA, L. S. Pure micropapillary rectal carcinoma with CK7 and CK20 coexpression and loss of CDX2 reactivity. Int. J. Morphol., 30(1):25-29, 2012.

SUMMARY: The micropapillary carcinoma is regarded as an aggressive variant of adenocarcinoma in any location. Histologically is characterized by papillary cell clusters surrounded by clear spaces. The reported proportion of micropapillary carcinoma component to the entire tumor ranged from 5 to $80 \%$ and no pure cases has been reported. There are near of 130 cases reported to date in colorectum. We experienced a patient with a pure micropapillary carcinoma showing coexpression of CK7, CK20, and absence of CDX2, which had an aggressive neoplasm with extense perineural, vascular and lymphatic invasion also extensive nodal metastasis. The presence of a micropapillary carcinoma in the colorectum seemed to be closely related with nodal metastasis, similar to the case for micropapillary carcinomas in other organs. Therefore, if a micropapillary component is identified in a tumor, particularly in a biopsy specimen, even if the pre-operative diagnosis is a pedunculated early colorectal cancer, should be carefully consider the extent of surgical resection due to the high potential for nodal metastasis.

KEY WORDS: Micropapillary carcinoma; Adenocarcinoma; CK7; CK20; CDX2; Colorectal cancer.

\section{INTRODUCTION}

The micropapillary carcinoma is regarded as an aggressive variant of adenocarcinoma in any location described, namely bladder, lung, pancreas, salivary glands and recently colon, rectum and stomach (Verdú et al., 2011; Amin et al., 2002; Amin et al., 1994; Nassar, 2004; Nassar et al., 2001; Paterakos et al., 1999; Siriaunkgul \& Tavassoli, 1993; Zekioglu et al., 2004). Histologically is characterized by papillary cell clusters surrounded by clear spaces. The reported proportion of micropapillary carcinoma component to the entire tumor ranged from 5 to $80 \%$ and no pure cases has been reported. In gastrointestinal tract the most reported location is the sigmoid and rectum (Haupt et al., 2007; Kim et al., 2006; Kuroda et al., 2007; Sakamoto et al., 2005; Wen et al., 2008; Xu et al., 2009). In total, are near of 130 cases reported to date in colorectum.

This variant had consistently showed that independently of their location is associated with lymphovascular invasion, lymph node metastasis and aggressive clinical behavior.

We present, to knowledge, the first case of pure micropapillary carcinoma, which also shows CK7 and CD20 coexpression and loss of CDX2 reactivity.

\section{CASE REPORT}

A 61-year-old Mexican men with cystoprostatectomy 2 years ago by a invasive High grade urothelial papillary carcinoma T1 N0 M0 (TNM staging system 7th edition) presented with an abdominal pseudo-occlusion syndrome for 1 month and was admitted in the Emergency Department of Mexico's National Cancer Institute and subsequently underwent a rectal low anterior resection. His clinical course was uneventful 1 month after the surgery.

The surgically resected specimen was processed accord to established protocols, in brief, the assessment is performed by direct visual inspection of the fresh specimen, and then the mesorrectal fat is inked about its circumferential resection margin including all non-peritonealised bare areas anteriorly and posteriorly. The rectum is opened anteriorly, apart from the segment $2 \mathrm{~cm}$ above and $2 \mathrm{~cm}$ below the tumor, where the specimen is left intact. Then the specimen is pinned on a corkboard to prevent shrinkage artifact and place a gauze in the lumen, the specimen fixes in $10 \%$ formalin by 48 hours. Passed this time, the unopened portion is then sliced into thin transverse sections $(3-5 \mathrm{~mm}$ in thickness). All off cross-sectional rings should be laid out to 
further assess the quality of the mesorectum and the relationship of tumor of the margin and the tumor was full submitted in cassettes and further are embedded in paraffin. Sections in 3 micrometers thick were stained with hematoxilin and eosin. After deparaffinization, antigen retrieval was performed using a Ventana automated immunostainer (Tucson, AZ) with mild CC1 reagent. Tissue sections were incubated with the antibodies; this was followed by washing and detection with the i-View DAB kit from Ventana. Antibodies employed in the present study are summarized in Table I and described below: CK 20 (Dako, Carpintera, California, clone 20.8 dilution 1:100), MUC-1 (Novocastra, Newcastle, England, clone Ma695, dilution 1:100), CKAE/1AE3 (Dako, Carpintera, California, clone AE1/AE3 dilution 1:200), CK7 (Dako, Carpintera California, Clone OV-TL 12/30, dilution 1:160), EMA (Dako, Carpintera California, clone E29, dilution 1:100), CDX2 (Abcam, Cambridge, England, Clone AMT28, dilution 1:50) and Uroplakin III (Research Diagnostics, Inc, Flanders, New Jersey, clone AU-1, dilution 1:100).

Table I. Summary of antibodies performed.

\begin{tabular}{lllr}
\hline Antibody & Laboratory & Clone & Dilution \\
\hline CK 20 & Dako, Carpintera CA & 20.8 & $1: 100$ \\
MUC-1 & Novocastra, Newcastle, UK & Ma695 & $1: 100$ \\
CKAE/1AE3 & Dako, Carpintera CA & AE1/AE3 & $1: 200$ \\
CK7 & Dako, Carpintera CA & OV-TL 12/30 & $1: 160$ \\
EMA & Dako, Carpintera CA & E29 & $1: 100$ \\
CDX2 & Abcam, Cambridge, UK & AMT28 & $1: 50$ \\
Uroplakin III & Research Diagnostics, Inc, Flanders, NJ & AU-1 & $1: 100$ \\
\hline
\end{tabular}
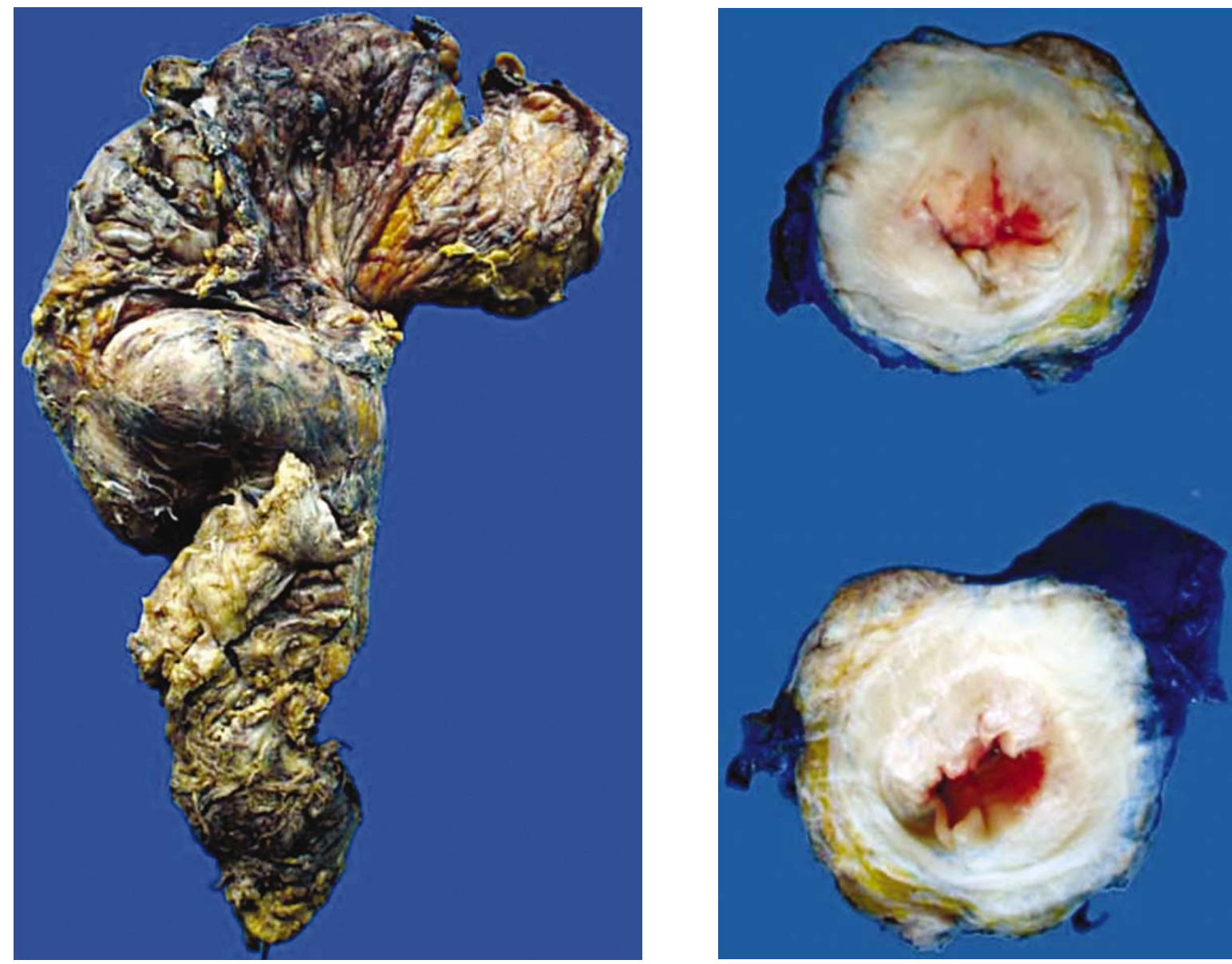

Fig. 1. The rectal specimen shows incomplete mesorectal excision (left) and a exophytic and ulcerant neoplasms infiltrating the whole rectal wall (right). 


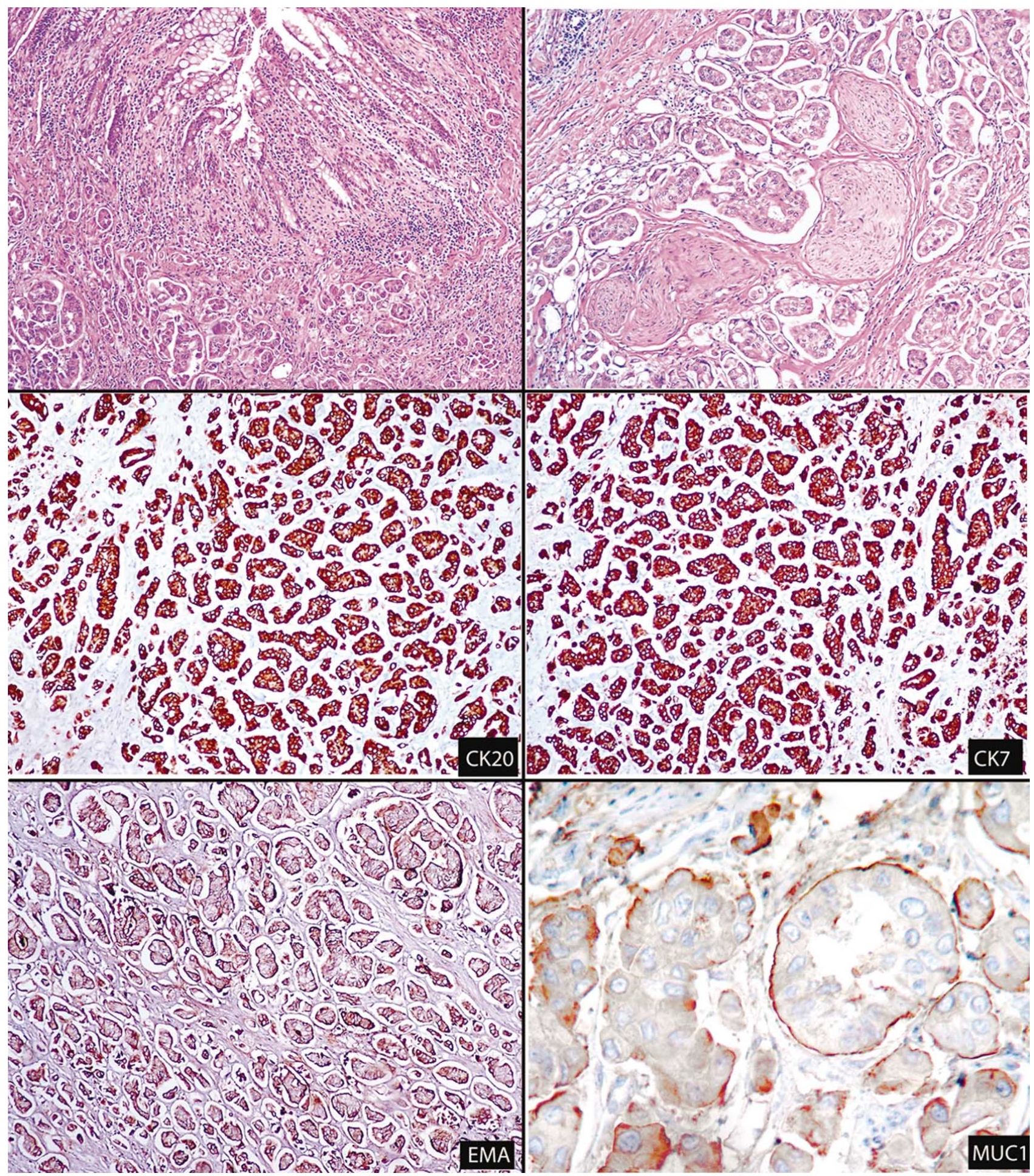

Fig. 2. There is a malignant gland-forming neoplasia diffusely infiltrating the submucosa. In the top of the image are the normal colonic mucosa (A). The classic pattern of infiltration of micropapillary carcinoma consists in nests and glandular structures with focal papillary projections without fibrovascular cores lying within clear stromal spaces reminiscent of vascular lumens (B). The neoplastic cells are positive to CK 20 (C), CK7 (D), EMA (E) and MUC-1 (F); the last two shows the classic "reverse polarity pattern".

Pathological findings. Macroscopically, the tumor was intraluminal, localized in the rectum over the anterior peritoneal reflextion a $6 \mathrm{~cm}$ of the nearest margin (distal). The neoplasms was a exophitic and infiltrant bulky mass, 
which measured --6.0 x $5.0 \times 4.0 \mathrm{~cm}$, was observed in the rectum (Fig. 1). Microscopically, there is a neoplastic proliferation of atypical glandular cells disposed in nests and glandular structures with focal papillary projections without fibrovascular cores lying within clear stromal spaces reminiscent of vascular lumens (Fig. 2A,B). There was a very focal natural transition between conventional tubular carcinoma in small focus and micropapillary carcinoma $(>95$ $\%$ of the total tumor area). In depth, the tumor invaded into the subserosal layer. Marked infiltration into lymphatic vessels and veins was observed, also perineural invasion, neoplastic cells in distal and circumferential margin and metastasis in 21 of 22 regional lymph nodes were present.

The neoplasm react immunohistochemically with CK20 (Fig.2C), CK7 (Fig.2D) and for MUC1 (Fig.2E) and EMA (Fig.2F) in the characteristic "inside-out" pattern.

\section{DISCUSSION}

Recently, micropapillary carcinoma has been reported in various anatomic sites. Except for the ovary, micropapillary carcinoma arising in many organs seems to pursue an aggressive clinical course because of frequent invasion into lymphatic spaces, metastasis into lymph nodes, or systemic metastasis (Verdú et al.; Amin et al., 2002; Amin et al., 1994; Nassar; Nassar et al.; Paterakos et al.; Siriaunkgul \& Tavassoli; Zekioglu et al.; Haupt et al.; Kim et al.; Kuroda et al.; Sakamoto et al.; Wen et al.; Xu et al.). Micropapillary carcinoma of the colon macroscopically seems to be indistinguishable from conventional adenocarcinoma.

Microscopically, micropapillary carcinoma in the present case was not associated with conventional adenocarcinoma, contrary to all previous reports were the micropapillary component form part of a combined tumor, and is the less predominant component of such neoplasms. In the most large series recently published by Verdú et al., from a total of 379 cases finds 60 that have at least a 5\% of micropapillary carcinoma, it corresponds to 5-80\% of tumor, generally less of $30 \%$, and no found a pure example. These results are very similar to those obtained by Horuda et al. and Kim et al. In other report by Sonoo et al. (2009) presents a case of micropapillary carcinoma originated in a pedunculated polyp, and this pattern comprised $80 \%$ of the tumor and the remaining $20 \%$ was moderately differentiated tubular adenocarcinoma.

Thus, pure micropapillary carcinoma is extremely rare in any location. Our case represents the first pure micropapillary carcinoma reported to date in all colon and rectum.

Immunohistochemical study surprised us because CK7 expression, but there are studies that shows CK7 expression in poorly differentiated colorectal carcinomas in near of $10 \%$ of cases (Saad et al., 2009; Hernandez et al., 2005). Additionally, there are cases of absence of expression of cdx 2 in colorectal carcinoma in up 29\% of cases (Choi et al., 2006; Baba et al., 2009). At last, not exist to date a good designed study that explores the immunohystochemical panel to define the primary site of metastatic micropapillary carcinomas, only are one study exploring this issue (Lotan et al., 2009). Thus, the clinical and pathological data of our case are supportive of rectal origin.

In conclusion, we experienced a patient with a pure micropapillary carcinoma showing coexpression of CK7, CK20, and absence of CDX2, which had an aggressive neoplasm with extense perineural, vascular and lymphatic invasion also extensive nodal metastasis. The presence of a micropapillary carcinoma in the colorectum seemed to be closely related with nodal metastasis, similar to the case for micropapillary carcinomas in other organs. Therefore, if a micropapillary component is identified in a tumor, particularly in a biopsy specimen, even if the pre-operative diagnosis is a pedunculated early colorectal cancer, should be carefully consider the extent of surgical resection due to the high potential for nodal metastasis.

LINO-SILVA, L. S. Carcinoma micropapilar rectal puro con coexpresión de CK7 y CK20 y pérdida de reactividad CDX2. Int. J. Morphol., 30(1):25-29, 2012.

RESUMEN: El carcinoma micropapilar es considerado como una variante agresiva del cáncer en cualquier localización. Histológicamente se caracteriza por grupos de células papilares rodeada de espacios libres. Se informó que la proporción del componente carcinoma micropapilar en la totalidad de un tumor varió entre 5\% a $80 \%$ y no se han reportado casos puros. Existen cerca de 130 casos reportados hasta la fecha en colon y recto. Se describe el caso de un paciente con un carcinoma micropapilar puro que muestra coexpresión de CK7, CK20, y la ausencia de CDX2, que tenía un tumor agresivo con extensa invasión perineural, vascular y linfática además de metástasis nodular extensa. La presencia de un carcinoma micropapilar en la región colorrectal parece estar estrechamente relacionada con metástasis nodular, similar al caso del carcinomas micropapilar en otros órganos. Por lo tanto, si un componente micropapilar se identifica en un tumor, sobre todo en una muestra de biopsia, incluso si el diagnóstico pre-operatorio es un cáncer colorrectal temprano pediculado, se debe considerar cuidadosamente la extensión de la resección quirúrgica debido a la alta probabilidad de metástasis nodular.

PALABRAS CLAVE: Carcinoma micropapilar; Adenocarcinoma; CK7; CK20; CDX2; Cáncer colorrectal. 


\section{REFERENCES}

Amin, M. B.; Tamboli, P.; Merchant, S. H.; Ordóñez, N. G.; Ro, J.; Ayala, A. G. \& Ro, J. Y. Micropapillary component in lung adenocarcinoma: a distinctive histologic feature with possible prognostic significance. Am. J. Surg. Pathol., 26(3):358-64, 2002.

Amin, M. B.; Ro, J. Y.; el-Sharkawy, T.; Lee, K. M.; Troncoso, P.; Silva, E. G.; Ordóñez, N. G. \& Ayala, A. G. Micropapillary variant of transitional cell carcinoma of the urinary bladder. Histologic pattern resembling ovarian papillary serous carcinoma. Am. J. Surg. Pathol., 18(12):1224-32, 1994.

Baba, Y.; Nosho, K.; Shima, K.; Freed, E.; Irahara, N.; Philips, J.; Meyerhardt, J. A.; Hornick, J. L.; Shivdasani, R. A.; Fuchs, C. S. \& Ogino, S. Relationship of CDX2 loss with molecular features and prognosis in colorectal cancer. Clin. Cancer Res., 15(14):4665-73, 2009.

Choi, B. J.; Kim, C. J.; Cho, Y. G.; Song, J. H.; Kim, S. Y.; Nam, S. W.; Lee, S. H.; Yoo, N. J.; Lee, J. Y. \& Park, W. S. Altered expression of CDX2 in colorectal cancers. APMIS, 114(1):50-4, 2006.

Haupt, B.; Ro, J. Y.; Schwartz, M. R. \& Shen, S. S. Colorectal adenocarcinoma with micropapillary pattern and its association with lymph node metastasis. Mod. Pathol., 20(7):729-33, 2007.

Hernandez, B. Y.; Frierson, H. F.; Moskaluk, C. A.; Li, Y. J.; Clegg, L.; Cote, T. R.; McCusker, M. E.; Hankey, B. F.; Edwards, B. K. \& Goodman, M. T. CK20 and CK7 protein expression in colorectal cancer: demonstration of the utility of a populationbased tissue microarray. Hum. Pathol., 36(3):275-81, 2005.

Kim, M. J.; Hong, S. M.; Jang, S. J.; Yu, E.; Kim, J. S.; Kim, K. R.; Gong, G. \& Ro, J. Y. Invasive colorectal micropapillary carcinoma: an aggressive variant of adenocarcinoma. Hum. Pathol., 37(7):809-15, 2006.

Kuroda, N.; Oonishi, K.; Ohara, M.; Hirouchi, T.; Mizuno, K.; Hayashi, Y. \& Lee, G. H. Invasive micropapillary carcinoma of the colon: an immunohistochemical study. Med. Mol. Morphol., 40(4):226-30, 2007.

Lotan, T. L.; Ye, H.; Melamed, J.; Wu, X. R.; Shih, IeM. \& Epstein, J. I. Immunohistochemical panel to identify the primary site of invasive micropapillary carcinoma. Am. J. Surg. Pathol., 33(7):1037-41, 2009.

Nassar, H. Carcinomas with micropapillary morphology: clinical significance and current concepts. Adv. Anat. Pathol., 11(6):297303, 2004.

Nassar, H.; Wallis, T.; Andea, A.; Dey, J.; Adsay, V. \& Visscher, D. Clinicopathologic analysis of invasive micropapillary differentiation in breast carcinoma. Mod. Pathol., 14(9):836-41, 2001.

Paterakos, M.; Watkin, W. G.; Edgerton, S. M.; Moore, D. H. 2nd. $\&$ Thor, A. D. Invasive micropapillary carcinoma of the breast: a prognostic study. Hum. Pathol., 30(12):1459-63, 1999.

Sakamoto, K.; Watanabe, M.; De La Cruz, C.; Honda, H.; Ise, H.; Mitsui, K.; Namiki, K.; Mikami, Y.; Moriya, T. \& Sasano, H. Primary invasive micropapillary carcinoma of the colon. Histopathology, 47(5):479-84, 2005.

Saad, R. S.; Silverman, J. F.; Khalifa, M. A. \& Rowsell, C. CDX2, cytokeratins 7 and 20 immunoreactivity in rectal adenocarcinoma. Appl. Immunohistochem. Mol. Morphol., 17(3):196-201, 2009.

Siriaunkgul, S. \& Tavassoli, F. A. Invasive micropapillary carcinoma of the breast. Mod. Pathol., 6(6):660-2, 1993.

Sonoo, H.; Kameyama, M.; Inatugi, N.; Nonomura, A. \& Enomoto, Y. Pedunculated polyp of early sigmoid colon cancer with invasive micropapillary carcinoma. Jpn. J. Clin. Oncol., 39(8):523-7, 2009.

Verdú, M.; Román, R.; Calvo, M.; Rodón, N.; García, B.; González, M.; Vidal, A. \& Puig, X. Clinicopathological and molecular characterization of colorectal micropapillary carcinoma. Mod. Pathol., 24(5):729-38, 2011.

Wen, P.; Xu, Y.; Frankel, W. L. \& Shen, R. Invasive micropapillary carcinoma of the sigmoid colon: distinct morphology and aggressive behavior. Int. J. Clin. Exp. Pathol., 1(5):457-60, 2008.

Xu, F.; Xu, J.; Lou, Z.; Di, M.; Wang, F.; Hu, H. \& Lai, M. Micropapillary component in colorectal carcinoma is associated with lymph node metastasis in T1 and T2 Stages and decreased survival time in TNM stages I and II. Am. J. Surg. Pathol., 33(9):1287-92, 2009.

Zekioglu, O.; Erhan, Y.; Ciris, M.; Bayramoglu, H. \& Ozdemir, N. Invasive micropapillary carcinoma of the breast: high incidence of lymph node metastasis with extranodal extension and its immunohistochemical profile compared with invasive ductal carcinoma. Histopathology, 44(1):18-23, 2004.

\section{Correspondence to: Leonardo Saúl Lino Silva, MD \\ Avenida San Fernando No. 22, \\ Colonia Sección XVI \\ C.P. 14080, México City \\ MÉXICO}

Email: saul.lino.sil@gmail.com
Received: 03-06-2011 Accepted: 22-10-2011 